\title{
PERFILES
}

\section{Ricardo Falcón (1945-2010).}

\section{Alcances y limites de una propuesta historiográfica para el estudio del mundo de los trabajadores en Argentina}

\author{
Lucas Poy \\ (UBA - CONICET)
}

La tarea del historiador implica siempre el desafio de formular nuevas preguntas, plantear renovadas hipótesis y proponer enfoques originales, pero al mismo tiempo revisar, releer y recuperar -a la luz, como no puede ser de otra manera, de las inquietudes que plantea el presente- el trabajo de aquellos autores que dejaron su impronta en la historiografia. Es con ese objetivo que Archivos se ha planteado desde su lanzamiento la tarea de dedicar un artículo de cada número a trazar un "perfil" de destacados investigadores del área, con el fin de analizar críticamente sus aportes a la historia de los trabajadores y la izquierda. Si en los primeros dos números la sección estuvo dedicada a historiadores extranjeros como David Montgomery y Georges Haupt, en esta ocasión consideramos importante revisar el trabajo de quien ha realizado una de las más importantes contribuciones a la historia de los trabajadores en Argentina: tómese este examen crítico de su obra como una reivindicación de sus aportes a la historia de los trabajadores en nuestro país y una reflexión sobre las líneas de trabajo que, a partir de sus reflexiones, pueden ser recuperadas en tanto siguen en agenda para investigaciones futuras.

\section{Entre Rosario y Paris, entre la militancia y la academia}

Ricardo Miguel Falcón nació en Rosario en 1945. Esa "Barcelona argentina", cuna de un formidable movimiento obrero desde fines del siglo XIX, fue no solamente el objeto de estudio de muchas de sus investigaciones sino su lugar en el mundo: con la excepción del periodo 1964-1969 -cuando residió en Buenos Aires-, y de los años del exilio, durante la última dictadura militar, allí vivió durante casi toda su vida, hasta su muerte en 2010. Su labor como historiador del movimiento 
obrero comenzó en su madurez, cuando superaba los treinta años: durante su juventud se dedicó a protagonizar, antes que a investigar, la historia de los trabajadores y la izquierda, gracias a una destacada militancia política de más de una década. Luego de un breve paso por el PRT La Verdad, el grupo dirigido por Nahuel Moreno, Falcón se incorporó a fines de la década de 1960 a las filas de Política Obrera (PO), agrupamiento también trotskista dirigido desde 1964 por Jorge Altamira, antecesor del actual Partido Obrero.

Pronto se convirtió en un dirigente del partido en su ciudad natal. Según María de los Ángeles Yannuzzi, ya en 1971 Falcón era el responsable político de PO en la ciudad de Rosario y "tenía a su cargo los seminarios internos de formación política" (2011: 45). Debido a su papel dirigente como responsable de la regional, Falcón no tardó en ser parte de la dirección nacional: ese mismo año participó en un plenario que fundó la organización juvenil nacional de PO, en la localidad bonaerense de Castelar, y más tarde sería incorporado al comité central. Falcón había trabajado como periodista en Radio Belgrano, en Buenos Aires, y en el diario Hoy de Rosario y cursado estudios de Historia y Derecho en la UBA y en la UNR, que quedaron incompletos (Gotta y Mugica, 2008: 68). Tal como hicieron numerosos jóvenes militantes de PO en ese período, decidió "proletarizarse" e ingresó a trabajar como obrero del frigorífico Swift. Participó activamente en la huelga de Villa Constitución, en 1974: durante ese conflicto, en un allanamiento policial a su domicilio, cuando el propio Falcón se encontraba ausente, fueron detenidos varios militantes de PO que quedaron a disposición del Poder Ejecutivo; entre ellos Néstor Correa, actual dirigente de la gremial docente de la UBA, y Bernardo Gallitelli, primo de Falcón, que se desempeñaba como obrero de Acindar. Falcón permaneció en Rosario algún tiempo después del golpe de marzo de 1976: otro militante rosarino de PO, Gustavo Spektor, recuerda que debieron pasar la noche en un hotel de Constitución en enero de 1977, luego de que ambos escaparan de Rosario debido a un secuestro reciente de dos compañeros. ${ }^{1}$

Fue entonces cuando, tras un paso por Brasil, Falcón decidió exiliarse en París. En dicha ciudad existía una amplia comunidad de exiliados politicos argentinos, que desarrollaban una importante actividad militante tanto en el seno de sus propias organizaciones como en el marco de diferentes agrupamientos de solidaridad con las víctimas de la represión y de defensa de los derechos humanos. Politica Obrera, en particular, tenía un importante trabajo en Francia,

1. Agradezco los aportes de Osvaldo Coggiola, Néstor Correa, Gustavo Spektor, Jorge Gelman, Juan Ferro, Christian Rath y Andrés Roldán, compañeros de militancia de Ricardo Falcón que contribuyeron a esta sección con diferentes recuerdos y apreciaciones sobre su actividad política en los años 70 . 
entre otras cosas por sus vínculos con la Organisation Communiste Internationaliste, partido dirigido por Pierre Lambert que compartió hasta 1978 un agrupamiento internacional con PO y otros grupos trotskistas, como el POR boliviano de Guillermo Lora. Marina Franco señala que en París "había un núcleo significativo [de Política Obrera] que mantuvo militantes dentro del CAIS (Comité Argentino de Información y Solidaridad) y, especialmente, en el TYSAE (Trabajadores y Sindicalistas Argentinos en el Exilio)" (2008: 112). En este marco, y ya en París, Falcón siguió vinculado a la militancia en PO, al tiempo que desarrollaba sus estudios de grado y posgrado en Historia. Existía, de hecho, todo un núcleo de militantes y simpatizantes de $\mathrm{PO}$ volcados al estudio de esa disciplina: Osvaldo Coggiola, Jorge Gelman, Edgardo Bilsky, Diana Quattrocchi, Zacarias Moutoukias, Bernardo Gallitelli y el propio Falcón, entre otros.

Durante los primeros años del exilio la actividad académica-profesional de Falcón y varios de los exiliados de PO continuó vinculada a una intervención política y militante: el primero de sus artículos, dedicado a analizar la "lucha de tendencias" al interior del Partido Socialista argentino en los años finales del siglo XIX, fue de hecho publicado en una revista llamada Apuntes para la historia del movimiento obrero e internacionalista latinoamericano, editada en Ámsterdam y vinculada claramente a la militancia internacional de PO (Falcón, 1979). Si bien el campo de interés de las investigaciones de Falcón ya se constituía claramente en torno al periodo formativo del proletariado argentino, dedicó algún tiempo a examinar la resistencia obrera a la dictadura, una inquietud sin dudas relacionada con su militancia política que se plasmó en un trabajo publicado en Ámsterdam en 1982, en una compilación editada por Andrés Thompson y Bernardo Gallitelli y reelaborado para una republicación en Argentina casi quince años más tarde (Falcón, 1982, 1996).

Con el correr de los años, de todas formas, la actividad académica de Falcón comenzó a tomar un vuelo propio: si bien continuó vinculado a PO hasta 1981, encontramos que su trabajo intelectual se aleja del vínculo con los militantes exiliados al tiempo que se estrecha la relación con historiadores profesionales franceses. Quien jugará aquí un rol fundamental es Robert Paris, destacado historiador del movimiento obrero y la izquierda, con quien Falcón establecerá un vínculo que marcará su formación profesional: mientras desenvolvía su investigación doctoral en la École des Hautes Études en Sciences Sociales (EHESS), sobre los orígenes del movimiento obrero argentino, Falcón formaba parte del equipo que elaboraba un "Diccionario Biográfico del Movimiento Obrero Latinoamericano", bajo la dirección de Paris y con la participación de otros jóvenes investigadores argentinos, como Eduardo Bittloch, Bil- 
sky y Gallitelli. ${ }^{2}$ Falcón también estableció un vínculo con Madeleine Rebérioux, otra destacada investigadora de la historia del movimiento obrero, que sería la directora de su tesis de doctorado.

Al tiempo que desarrollaba su formación en la EHESS, Falcón fue alejándose politicamente de PO: los debates en torno a la guerra de Malvinas, su participación en las reuniones convocadas por Hipólito Solari Irigoyen en París junto a otros exiliados argentinos y, más en general, todo un clima de época que apuntaba a una revalorización de la "democracia", dan marco a un replanteo político que llevó a nuestro autor a depositar, como muchos otros intelectuales, una fuerte expectativa en la propuesta política de Raúl Alfonsín. Rastreando el proceso compartido que los llevó de la militancia de izquierda a las simpatías por la propuesta alfonsinista, Hugo Quiroga señaló que, en esos años iniciales de la década de 1980, lecturas "de Gramsci, de Aricó, de Poulantzas, de Perry Anderson, de Agnes Heller, de André Gorz" los habian llevado "a comprender que era imposible la vía al socialismo sin instituciones democráticas". Según Quiroga, "este recorrido acentuó el estudio de Ricardo por la historia del movimiento obrero, antes que seguir pensando en la creación de un partido proletario" (2011: 67).

Falcón retornó a la Argentina y a su Rosario natal en mayo de 1984, en este contexto marcado por el entusiasmo de toda una generación de ex militantes de izquierda por las oportunidades que abria la "primavera democrática". A poco de su llegada se vinculó con la Universidad de Rosario, que se encontraba como otras en pleno proceso de renovación: su primera participación en la vida universitaria argentina fue el dictado de un seminario final sobre historia del movimiento obrero en la Facultad de Humanidades y Artes, así como un curso para graduados sobre "Pensamiento argentino y latinoamericano". A comienzos de 1985 volvió a París para defender su tesis de doctorado frente a un jurado integrado por Rebérioux, Paris y Ruggiero Romano. Luego retornó definitivamente a la Argentina y se radicó en Rosario, integrándose ya formalmente a la universidad: en octubre de ese año un jurado integrado por Hilda Sabato, Leandro Gutiérrez y Waldo Ansaldi lo declaró ganador de un concurso de titular de la materia Historia Política Argentina en la Facultad de Ciencia Politica y Relaciones Internacionales.

Sería en esa facultad donde Falcón desempeñaría desde entonces su actividad académica, dictando, además, clases de Historia Latinoamericana Contemporánea. Junto a las tareas docentes, reforzó rápidamente su labor como investigador, luego de su ingreso al CONICET en

2. Una parte de la investigación realizada bajo la dirección de Paris sirvió de insumo para un artículo publicado recién a comienzos de la década de 1990: Falcón, Macor y Monserrat (1991). 
1988. Falcón se destacaría particularmente como un gran formador de jóvenes investigadores, interesados en la historia del movimiento obrero en nuestro país y especialmente en Rosario. Participó también en la creación de distintas redes y espacios académicos en ese contexto de reactivación y renovación que caracterizaba a la década de 1980: si en su propia unidad académica creó el Centro Interdisciplinario de Estudios Sociales Argentinos y Latinoamericanos, que editaria los Cuadernos del CIESAL, se integró también a iniciativas de mayor alcance interregional, como la revista Estudios Sociales, vinculada a la UNR, la UNL de Santa Fe y la Universidad del Comahue, y un "Grupo de Estudio de los Sectores Populares y el Movimiento Obrero", surgido luego de la realización de las primeras Jornadas Interescuelas/Departamentos de Historia en 1988.

Desde entonces y hasta su muerte, Falcón desarrolló su actividad docente y profesional en el marco del CONICET y la UNR: además de la edición de partes de su tesis doctoral en la colección del Centro Editor de América Latina, a mediados de la década de 1980, publicó más de una decena de artículos en diversas revistas y compilaciones, participó como editor en una obra sobre el movimiento obrero argentino editada en Londres y New Jersey (Falcón, Munck y Gallitelli, 1987), coordinó un tomo de la colección Nueva historia argentina de Editorial Sudamericana (Falcón, 2000a) y, en 2005, publicó un nuevo libro dedicado a los orígenes del movimiento obrero rosarino. Su larga lucha contra una enfermedad que finalmente lo llevó a la muerte dificultó crecientemente su actividad como formador de investigadores y lo fue alejando progresivamente de la producción historiográfica.

La prioridad que dio a la actividad profesional y académica, si bien se enmarcó como vimos en un proceso de alejamiento de la militancia revolucionaria que había desarrollado en su juventud, no implicó el cierre de sus inquietudes politicas. En el marco del acercamiento al alfonsinismo que caracterizó a muchos intelectuales de su generación, Falcón formó parte de la filial rosarina del Club de Cultura Socialista, que según Silvana Carozzi "nunca tuvo la solidez del contemporáneo porteño, pero llegó a concretar alguna serie muy corta de reuniones" y cuya actividad se extendió hasta entrada la década de 1990 (2011: 38). El fracaso de la experiencia radical provocó en Falcón, como en muchos otros que habian abrigado ilusiones similares en el gobierno de Alfonsin, un relativo retraimiento de la actividad política: la inquietud por encontrar un marco político de referencia lo llevó de todas formas a acercarse e incluso afiliarse al socialismo santafesino, que gobierna la ciudad de Rosario desde mediados de la década de 1990 y la provincia desde 2007. Falcón encontró así, en los años finales de su vida, un "reencuentro" entre sus temas de investigación y su militancia política: 
su muerte dejó trunco el proyecto de escribir una historia general de las primeras épocas del PS, algunos de cuyos capitulos fueron publicados en forma póstuma en 2011 (ver Falcón, 2011a y 2011b).

\section{"Una historia de los trabajadores con pretensión de globalidad"}

Realizar una caracterización historiográfica de la obra de Ricardo Falcón no resulta una tarea sencilla, en primer lugar porque se trata de un autor que pocas veces incluyó en sus trabajos una referencia a las fuentes teóricas y metodológicas en las que abrevaba. Sin dudas su obra se enmarca, de un modo general, en el contexto de renovación que tuvo lugar en la década de 1980 y en el cual jugó un papel destacado el interés por la historia de los trabajadores en el periodo pre-peronista. Los trabajos de Falcón, como los del equipo de historiadores del PEHESA (Luis Alberto Romero, Leandro Gutiérrez, Ricardo González, Juan Carlos Korol, Hilda Sabato), pueden ser leídos en este sentido como expresión de una nueva producción intelectual que señaló los límites de las viejas "historias militantes", hasta entonces dominantes en la historiografia del movimiento obrero.

Esta visión, sin embargo, es demasiado simplificadora y se hace necesario un análisis más complejo. Las elaboraciones de los autores vinculados al PEHESA se trazaron toda una propuesta de trabajo que implicaba reexaminar la historia de los trabajadores con el objetivo de buscar rastros de una experiencia democrática que, a pesar de haberse visto empañada una y otra vez a lo largo del siglo XX, debía "anidar" de un modo u otro en diferentes espacios de la sociedad civil. Aunque se reivindicaba explícitamente la institucionalización de la actividad de los historiadores y la necesidad de que las investigaciones tuvieran un carácter profesional, alejado de inquietudes militantes, lo cierto es que la distancia entre historia y compromiso político se exigía más en relación con las corrientes de izquierda que con la experiencia alfonsinista, con la cual los miembros fundadores del PEHESA comulgaban explícitamente. Este énfasis en la diferenciación con la historia clásica del movimiento obrero, que llevó pocos años más tarde a plantear el rechazo a la utilización del concepto de "clase obrera" y a su reemplazo por el de "sectores populares", inseparable de ese contexto político de reivindicación de la experiencia democrática de los 80 , es por cierto menos identificable en los trabajos de Falcón. Si es indudable que su alejamiento de Política Obrera coincidió con una creciente simpatía y afinidad con el gobierno radical, no es menos cierto que su vínculo con los intelectuales del PEHESA, radicados en Buenos Aires, es menos directo y que su perfil historiográfico muestra aportes peculiares, que 
responden a influencias teóricas e intelectuales más complejas que deben ser examinadas.

En primer lugar, la propia trayectoria militante de Falcón jugó un papel sin dudas importante en su formación intelectual: como hemos visto, incluso en los años del exilio siguió vinculado a un grupo de militantes dedicados al estudio de la historia y activo en las filas de la comunidad política de exiliados. A esto debemos sumar la fundamental influencia que jugó en su formación el contacto con la escuela francesa de historia de la izquierda y el movimiento obrero: Falcón fue, en gran medida, un discipulo de investigadores de la talla de Paris, Haupt y Rebérioux. Tanto su formación militante como su vínculo con la escuela de historiadores franceses contribuyeron a delinear en Falcón una inquietud por la historia política del movimiento obrero y las izquierdas, mucho menos presente en otros historiadores del contexto de la renovación historiográfica argentina de los años $80 .{ }^{3}$

Sin dudas estas influencias en las cuales abrevó Falcón a fines de la década de 1970 y comienzos de la siguiente deben ponerse en relación con ese contexto más general de lecturas y relecturas que caracterizaba a muchos intelectuales de la época, en el cual los historiadores marxistas británicos ocupaban sin duda un lugar destacado: Agustina Prieto recuerda cómo en 1984 Falcón "irrumpió, flaco y desgarbado, en el páramo académico que era entonces la Facultad de Humanidades y Artes de Rosario, con el bolso de cuero azul lleno de fichas y el libro de E.P. Thompson, The making of the English working class" (2011: 18). Lo que nos interesa destacar aquí, en todo caso, es que las influencias que dieron forma a la perspectiva historiográfica de Falcón son ciertamente múltiples. Enrique Mases señaló en este sentido que lo caracterizaba un "eclecticismo militante", en tanto "en cada uno de los temas las fundamentaciones teóricas recurrian a una gama sumamente heterogénea de autores disímiles" (2011: 50-51).

Sus reflexiones historiográficas más explícitas pueden encontrarse en dos trabajos relativamente poco conocidos, publicados en el extranjero: uno en una revista costarricense (Falcón, 1988) y otro en una compilación editada en Uruguay (Falcón, 1989). Citando a George Haupt, allí reconocia que la aparición de una "historiografia universitaria" intere-

3. Diego Armus (2011) ha insistido en la importancia de esta influencia francesa en la formación de Falcón: profundizando en la misma línea, Fernando Devoto subrayó que "no eran las ingeniosas invenciones de la llamada tercera generación de Annales las que parecen haberlo atraído, sino aquel clima que podía percibirse en torno a la reconocida revista Le Mouvement Social", una publicación que estaba abierta "a las novedades metodológicas", pero "no dejaba de conservar una fuerte relación con la tradición erudita y con los temas y modos de enfoque clásicos de la historia obrera" (2011: 85). 
sada en la historia de los trabajadores tomaba sus fuentes fundamentales en autores como E.P. Thompson, Eric Hobsbawm, Michelle Perrot y Rollande Trempé. Lo interesante de su lectura es que señalaba que, más allá de estas fuentes bibliográficas, esta renovación historiográfica debía ponerse en relación con una serie de cambios políticos e ideológicos que daban lugar "a un nuevo tipo de relación entre los intelectuales y la política", caracterizada por una "desacralización de la clase obrera" y su potencial revolucionario. Pero si a nivel internacional esto podía plantearse aún en el terreno de la llamada "nueva izquierda", que al calor de los acontecimientos de fines de la década de 1960 revisó muchos de los planteos de los partidos tradicionales sin alejarse del activismo en diversos movimientos sociales, en Argentina estos cambios se procesaron en un terreno mucho más alejado de la izquierda y de los trabajadores, por los cuales las discusiones se mantuvieron por lo general en el terreno académico antes que en el político (1988: 164).

A partir de estos señalamientos, Falcón intentaba tomar una posición de dificil equilibrio frente a las elaboraciones del PEHESA: sostenía que "la puesta entre paréntesis del concepto de clase obrera en las primeras épocas de la historia de los trabajadores en Argentina no puede menos que parecernos saludable, aunque no compartamos todos sus análisis" (1988: 165). Según su lectura, los nuevos enfoques presentaban "algunos riesgos importantes de unilateralidad", en tanto si antes "lo político" era lo dominante, ahora el auge de "lo social" o "lo cultural" parecía excluirlo (1989: 150). Recomendaba explícitamente, en este punto, un abordaje capaz de desarrollar una interpretación que combinara los elementos "sociales", priorizados por la renovación historiográfica, con los elementos "políticos" característicos de la historiografia obrera más tradicional.

Falcón solía referirse a esta propuesta como una "historia de los trabajadores con pretensión de globalidad": si bien era inevitable que los estudios particulares examinasen aspectos parciales, sea temáticos, cronológicos o regionales, siempre se debía apuntar a elaborar conclusiones de conjunto que integrasen diferentes inquietudes parciales. Diferenciándose de las obras de los investigadores del PEHESA, señalaba:

Saber cómo los trabajadores vivian su propia existencia, conocer sus prácticas cotidianas, tratar de detectar la 'cultura' dominante -o las formas de cultura- son tareas de primer orden. Pero estas formas de pensamiento popular fragmentarias no se expresan al margen de las propuestas ideológicas de un pensamiento más sistemático lanzadas por los distintos actores sociales e incluso por las elites dirigentes del movimiento obrero. Hay una relación reciproca. (1988: 172) 
Su conclusión era que la utilización del término "sectores populares" podía ser correcta "para los primeros períodos de la historia de los trabajadores en Argentina, por lo menos hasta la última década del siglo XIX, en la medida que la indiferenciación social y política en la masa de trabajadores de la época es muy grande". Su empleo para periodos posteriores, sin embargo, resultaba problemático, en tanto "a partir de entonces el empleo de 'sectores populares' supone que la clase obrera no se ha constituido aún". Su opción, en este punto, era analizar "el proceso de construcción, de constitución, permanente de la clase obrera -y no de su simple determinación por los grados de industrializacióntal como lo hace E.P. Thompson" (1989: 164-165).

\section{Lo social y lo politico en el proceso de formación de la clase obrera}

Todo este cruce de influencias en la formación de Falcón puede ser rastreado en su obra. La preocupación por la historia política e intelectual de las corrientes activas en el mundo de los trabajadores se advierte no solo en el citado primer artículo, sobre la lucha de tendencias en el Partido Socialista de fines del siglo XIX, sino en otro elaborado poco tiempo más tarde -aunque publicado recién en 1985-, en el marco de un seminario dictado por Robert Paris, y dedicado a examinar la figura de José Ingenieros. Se trata de un trabajo en el cual es posible advertir una continuidad de la preocupación por las etapas tempranas del socialismo local al mismo tiempo que una inquietud por la historia intelectual y de las ideas, característica de la escuela francesa en la cual estaba haciendo sus primeras armas como investigador (Falcón, 1985b). Algunos años más tarde, ya de regreso en Argentina, Falcón publicó junto a Hugo Quiroga un trabajo sobre la historia reciente del Partido Comunista: si a priori puede parecer un tema relativamente alejado de las preocupaciones que guiaron su trabajo historiográfico, muestra sin embargo la persistencia de esta inquietud por la historia política de la izquierda (Falcón y Quiroga, 1987).

Aunque la tesis doctoral de Falcón, L'Immigration, les travailleurs et le mouvement ouvrier en Argentine, 1870-1914, nunca fue publicada como tal, ni en francés ni en español, fue a partir del trabajo contenido en esa investigación que surgieron las que probablemente sean sus obras más influyentes: los dos libros que, con un intervalo de dos años, publicó en la famosa colección del Centro Editor de América Latina (1984 y 1986): Los orígenes del movimiento obrero (1857-1899), por un lado, y El mundo del trabajo urbano (1890-1914), por el otro. A pesar de tratarse de trabajos no muy extensos, como por otra parte era habitual en las publicaciones de dicha colección, los libros alcanzaron una amplia repercusión y se 
convirtieron en obras de referencia obligada para todos los interesados en las etapas tempranas del movimiento obrero local, en un contexto de revitalización del interés por la historia de los trabajadores.

Ambos libros muestran una serie de importantes elementos comunes, que ponen de manifiesto que son el producto de una misma investigación. En primer lugar, se ponía de relieve la preocupación de Falcón por abordar el estudio del período formativo del movimiento obrero, ya presente en sus primeros artículos, con una perspectiva que fuera más allá de los abordajes que habían predominado en la "historiografia militante" pero sin perder de vista un examen de los clivajes políticos de la historia del movimiento obrero. Tal como señalaba en la introducción del primero de sus libros, se planteaba la tarea de estudiar los orígenes del movimiento obrero argentino en relación con las transformaciones sociales acaecidas como consecuencia del proceso inmigratorio y las transformaciones del capitalismo local, pero ello no negaba "la necesidad de estudiar también sus aspectos políticos, ideológicos e incluso el papel desempeñado por los individuos" (Falcón, 1984a: 10).

Falcón se dio a la tarea de examinar "los orígenes del movimiento obrero argentino en directa relación con el proceso de conformación de la clase obrera y del conjunto de transformaciones sociales de la época" (1984a: 9). Esa doble inquietud estructura todo el trabajo: la primera parte está dedicada a analizar la formación de una capa de artesanos y trabajadores urbanos, desde la década de 1850, y el modo en que en ese marco social se desarrollaron las primeras experiencias organizativas -en forma de mutuales y primeras sociedades de oficios- de los trabajadores. En este punto se inscribe uno de los principales aportes del libro, producto de la investigación realizada en el IISG de Ámsterdam: la reconstrucción de la experiencia de los militantes vinculados a la AIT en Buenos Aires, durante los primeros años de la década de 1870. La segunda parte del libro continúa con este doble abordaje, pero para un período posterior: si en primer término se examina el proceso de "formación del proletariado" que, al calor de las transformaciones económicas y sociales que acompañaron a la consolidación del capitalismo local, tuvo lugar en las últimas dos décadas del siglo XIX, se complementaba ese análisis con la dinámica de estructuración del "movimiento obrero" y las corrientes anarquistas y socialistas.

El mundo del trabajo urbano se adecuaba más a las nuevas inquietudes dominantes en la historiografia de los 80: allí Falcón se concentraba menos en la historia politica del movimiento obrero y otorgaba una atención privilegiada a examinar las "condiciones de vida" de los trabajadores, extendiendo por otra parte el análisis hasta 1914. Falcón proponía así una mirada que buscaba ir más allá de un análisis de las condiciones de trabajo experimentadas por los obreros en fábricas o 
talleres. Sugería en este marco la utilización de la categoría "mundo del trabajo", entendido como "el conjunto de relaciones que los trabajadores individual y colectivamente establecen en la esfera de la producción, el ámbito de los lugares de trabajo, entre sí, con los patrones, con el Estado y con las organizaciones y movimientos que pretenden representarlos" (Falcón, 1986: 10). Con este objetivo, el libro exploraba las condiciones laborales del proletariado en este período temprano, dedicando especial atención al trabajo femenino e infantil, las características de los procesos de trabajo en fábricas y talleres, el trabajo a domicilio, etc. Pero además se examinaba el vínculo de los trabajadores con los patrones y el Estado, la estructuración de las primeras organizaciones obreras y, en un capitulo final, la "actitud" que los propios trabajadores desenvolvian ante su labor, configurando lo que Falcón llamó una particular "cultura del trabajo" que podía modificarse según el período, la zona o incluso la rama productiva que se tomara en consideración.

Posiblemente sea en este tramo final del libro donde se encuentran algunas de las hipótesis más sugerentes. Según Falcón, es posible advertir dos "tendencias" en cuanto a la actitud de los trabajadores frente a la cultura del trabajo, separadas cronológicamente por los años finales del siglo XIX. Si en un primer período era dominante una "cultura" menos conflictiva, en la cual se notaba el peso de cierta posibilidad de ascenso social que llevaba a muchos trabajadores a desarrollar una "autodisciplina" que les permitiera una mejora en su situación a través de su ingreso a las filas de los pequeños propietarios, en el segundo tramo ya es posible encontrar un mayor peso de la conflictividad y los choques de clase, que mostraban que para muchos obreros su posición social era inmodificable y lo que se planteaba era una lucha colectiva para mejorar sus condiciones de vida. Buena parte de estas reflexiones sobre la "cultura del trabajo" fueron recuperadas y ampliadas en un artículo publicado en una compilación editada por Diego Armus en 1990, Mundo urbano y cultura popular. Alli Falcón complejizaba algunos de los argumentos, planteando por ejemplo la interrelación entre transformaciones estructurales (mayor tamaño de las fábricas, mayor división del trabajo, aumento del disciplinamiento en el lugar de trabajo, debilitamiento de los oficios) y los cambios en la actitud colectiva y la "cultura del trabajo", que iba en conjunto con un fortalecimiento de los sindicatos y de la conflictividad huelguística. Al mismo tiempo reforzaba la idea de que, más allá de estas dos grandes tendencias que dominan en cada período, hay una "persistencia minoritaria en cada una de esas etapas de la tendencia antagónica a la dominante" (Falcón, 1990).

Fernando Devoto ha señalado que otro de los aspectos en los cuales puede advertirse la influencia de su formación francesa es en la preocupación de Falcón por incorporar la cuestión de la inmigración a su 
estudio de la formación del movimiento obrero. Más específicamente, encontramos en su obra una inquietud por el peso de las diferenciaciones nacionales y étnicas en el complejo proceso de estructuración de una identidad obrera, que debía absorber tradiciones cosmopolitas y diversas. En un importante artículo publicado en 1992, en una compilación editada por el propio Devoto y Eduardo Míguez, Falcón revisó el papel jugado por la "cuestión étnica" en el proceso de formación del movimiento obrero local. Alli destacaba, en primer término, la posibilidad de identificar cierta correlación entre grupos étnico-nacionales y pertenencia a determinados oficios o categorías profesionales. En segundo lugar, y en relación con lo anterior, Falcón mostró que es posible advertir la estructuración de una cierta "escala jerárquica" entre inmigrantes de diverso origen, desde los que ocupaban los oficios más calificados hasta aquellos vinculados a los trabajos de menor remuneración y calificación. Puso de manifiesto, además, que esta jerarquía fue modificándose con los años, a medida que la inmigración daba lugar a un predominio de diferentes grupos nacionales que ocupaban, en general, los lugares menos calificados y daban lugar así a un relativo "ascenso social" de grupos nacionales con una presencia de más larga data en el país. Por último, pero no menos importante, Falcón examinaba las dificultades que planteó esta heterogeneidad étnica para la estructuración de la clase obrera local, poniendo de relieve la existencia de conflictos y disputas interétnicas que eran contestadas por los sectores políticamente activos de la izquierda, partidarios de reforzar la unidad obrera más allá de las diferencias nacionales.

\section{E1 movimiento obrero, el régimen politico y la caracterización del yrigoyenismo}

Si en la preocupación por la historia política e intelectual de la izquierda y el movimiento obrero puede advertirse la influencia de su pasado militante y de su formación historiográfica en Francia, sin dudas hay otros aspectos de la producción de Falcón donde podemos encontrar un mayor peso de las inquietudes que marcaban a la generación de historiadores argentinos que se volcaron al estudio del mundo de los trabajadores en esos años. Uno de ellos es la pregunta acerca de la relación que se estableció entre ese naciente movimiento obrero y el Estado: si, por una parte, esa inquietud implicaba una reflexión acerca de los modos en que los gobiernos conservadores enfrentaron la llamada "cuestión social", por la otra llevaba también a un examen de los cambios que esa relación había mostrado con la llegada al poder de los radicales luego de la Ley Sáenz Peña. Los aportes de Falcón contribuyeron desde su lugar a esa lectura empática que surgía desde 
diferentes vertientes para con la experiencia radical de 1916-1930, en una operación que sin duda no puede desvincularse de la simpatía de muchos de los investigadores con el alfonsinismo.

Falcón abordó la cuestión a partir de un examen de la experiencia que tuvo lugar en su propia ciudad: en dos artículos publicados en 1992 y 1993, el segundo en colaboración con Alejandra Monserrat, estudió los cambios que se observan en la relación entre el Estado y el movimiento obrero en Rosario antes y después de la sanción de la Ley Sáenz Peña. Ocurre que fue en la provincia de Santa Fe donde tuvo lugar la primera experiencia de gobierno radical, desde 1912: para nuestro autor "significó un cambio sustancial, inédito hasta entonces en todo el país, en las relaciones entre el Estado y el movimiento obrero" (1993: 35) y constituía por lo tanto un laboratorio donde advertir muchos de los elementos que se plasmarian a nivel nacional desde 1916.

El aporte de Falcón y Monserrat constituía una propuesta original en dos sentidos: por un lado, discutía con la hipótesis de David Rock, que explicaba el acercamiento del radicalismo gobernante a los trabajadores a partir del objetivo de "incrementar las adhesiones electorales". Para los autores, existian "lazos previos" del radicalismo con los trabajadores que resultaban claves para entender que, una vez en el gobierno, los radicales no buscaron tanto "captar" apoyos obreros sino "mantener y solidificar esa relación" (1993: 31). En segundo lugar, la perspectiva de los autores complejizaba las lecturas simplistas que veían como incompatible la simpatía de muchos trabajadores con el radicalismo y la continuidad de prácticas sindicales clasistas: mostrando que el caballerismo santafesino era una peculiar experiencia que combinaba elementos nacionalistas y populares, Falcón y Monserrat sostenían que muchos trabajadores "volcaban sus preferencias politicas hacia el radicalismo, pero también participaban en las luchas sindicales dirigidas por la F.O.R. anarquista" (1993: 30). El elemento común era un "antipoliticismo y antiestatismo" que permitía "que trabajadores de simpatías radicales militaran sindicalmente con los anarquistas" (1993: 30).

Estos elementos novedosos en el examen de la relación Estadosindicatos en la Santa Fe de la década de 1910 se relacionan con la inquietud de Falcón por examinar las políticas sociales de los gobiernos radicales pero también con reflexiones que se desprendian de su estudio sobre las características del movimiento obrero en el período previo. En este sentido el mismo carácter de "bisagra" que une diferentes preocupaciones lo encontramos en el que tal vez sea su artículo más celebrado: "Izquierdas, régimen político, cuestión étnica y cuestión social (1890-1912)", publicado en 1987. El principal logro del artículo es que ponía en relación el estudio del movimiento obrero y el ascenso de la conflictividad social de comienzos del siglo XX con la crisis del 
régimen político oligárquico. $\mathrm{Si}$, por un lado, el debate que tuvo lugar en las filas de la oligarquía sobre posibles vías reformistas a la crisis se interpretaba a la luz de los condicionamientos que la propia agitación obrera planteaba a la dominación del "orden conservador", por otro lado se analizaban las diferentes propuestas politicas de las corrientes activas en el mundo del trabajo en directa relación con esa crisis, a la cual no solo la "elite" debía dar respuesta.

De este modo, la originalidad de la propuesta de Falcón consistía en dar una nueva respuesta a la pregunta sobre las causas que llevaban, en el movimiento obrero argentino antes del Centenario, a un predominio político de los anarquistas. A diferencia de interpretaciones previas -ligadas a un molde interpretativo esquemático de raigambre stalinista- que proponían como explicación el carácter "atrasado" de la clase obrera local, el peso del artesanado, o la influencia de inmigrantes de origen latino, Falcón desarrolló una hipótesis que corría el eje de una supuesta necesidad histórica dictada por condicionantes "estructurales" y proponia una lectura que devolvia la necesaria contingencia que surge de la lucha política. El éxito relativo de los anarquistas obedecía a su capacidad de dar una "respuesta" más satisfactoria que sus adversarios políticos a las principales cuestiones que estaban planteadas en esos años críticos: la relación con el régimen político, la posición frente a las luchas reivindicativas que enmarcaban la llamada "cuestión social" y la cuestión de la asimilación de los inmigrantes. Según Falcón, frente a un socialismo que consideraba las luchas reivindicativas y huelguísticas como un método arcaico y ponía en primer plano la vía parlamentaria, reclamando a los trabajadores que se nacionalizaran para participar de un sistema electoral fraudulento, resultó más eficaz la interpelación anarquista, que impulsaba un desenvolvimiento de las tendencias de lucha de los explotados sin requerir una nacionalización que era vista por muchos trabajadores como una elección con mayores costos que beneficios, dado el carácter fraudulento del régimen político y la posibilidad de mantener ciertos beneficios conservando el vínculo con sus comunidades nacionales de origen.

Desde mediados de la década de 1990 la producción de Falcón se hace más esporádica, al tiempo que sus planteos van perdiendo esa personalidad propia que los había caracterizado y se observa una mayor coincidencia con las posiciones de otros investigadores más vinculados a la experiencia del PEHESA. Esto puede advertirse en sus colaboraciones en la colección Nueva Historia Argentina, editada por Sudamericana: Falcón coordinó el tomo 6 , dedicado a las presidencias radicales, y escribió en el mismo dos artículos. El primero de ellos, escrito junto a Alejandra Monserrat y dedicado a examinar la dinámica del movimiento obrero en el período 1916-1930, nos muestra la versión más complaciente de 
Falcón para con las presidencias radicales: su examen destacará mucho más los intentos de Yrigoyen de intervenir en los conflictos laborales para ganarse la adhesión de los trabajadores que las fuertes medidas represivas tomadas durante esos años, presentadas en general como consecuencia indeseada de la presión provocada por los empresarios y sus organizaciones para-estatales, como la Liga Patriótica. El otro artículo de Falcón en ese tomo de la Nueva Historia Argentina, titulado "Militantes, intelectuales e ideas políticas", examinaba cuestiones menos trabajadas en su obra, como el desarrollo de un pensamiento antipositivista en los años posteriores al Centenario o el impacto de la revolución rusa en los medios políticos locales, que de todas formas ponian de manifiesto una continuidad de viejas preocupaciones de Falcón por la historia intelectual. También en este caso observamos un énfasis en los mecanismos de integración que habrian caracterizado al gobierno radical, en el marco de su examen sobre la influencia del pensamiento krausista en Yrigoyen: según Falcón, dicho pensamiento "habría contribuido dentro y fuera, antes y en el radicalismo, a la formación del Estado benefactor" (2000a: 330).

El último emprendimiento editorial de Falcón fue la publicación, en 2005, de La Barcelona argentina, un libro dedicado a examinar los orígenes del movimiento obrero rosarino. A pesar de su importancia, este demorado retorno de nuestro autor al formato libro no llegó a constituir la esperada obra de madurez que compilase buena parte de sus elaboraciones previas, y presenta un carácter heterogéneo que resiente la solidez de la obra. Según la descripción realizada por el propio autor en la introducción, se trata de un libro que reúne distintos tipo de trabajos: mientras algunos son "enteramente nuevos" o basados en ponencias, otros tramos reproducen informes inéditos presentados al CONICET y otros se basan en una "reescritura y reorganización" de trabajos individuales y colectivos ya editados. En efecto, una lectura atenta permite advertir la yuxtaposición de trabajos de distinto origen, lo cual lleva a algunas repeticiones y a cierta descompensación en el tratamiento de los temas. En los últimos años de su vida la producción historiográfica y la actividad profesional de Falcón se redujo a un mínimo, debido al avance de su enfermedad, si bien continuó participando en eventos académicos y dictando clases. Murió en su ciudad natal de Rosario, el 28 de junio de 2010.

\section{Balance: alcances y limites de un proyecto historiográfico}

Una mirada de conjunto sobre su obra pone de manifiesto que constituye uno de los más importantes aportes a la historiografia obrera 
de nuestro país, particularmente en la etapa anterior al peronismo. Si es indudable que podemos colocarlo en el contexto de reactivación de los estudios sobre el mundo de los trabajadores que tuvo lugar en la década de 1980, no pueden dejar de advertirse en la obra de Falcón una serie de características particulares, en buena medida producto de su experiencia militante en los 70 y de su contacto con la escuela de historiografia francesa en los años del exilio. El resultado fue una obra original, con cierto eclecticismo teórico, que aportó interpretaciones agudas y sugerentes sobre el período formativo del movimiento obrero nacional y regional, los vínculos entre cuestión étnica y cuestión social, diversos aspectos de la "cultura del trabajo" y la relación entre Estado y trabajadores, sin descuidar la historia política de las corrientes de izquierda e incluso el intento de reconstruir las biografias de centenares de militantes obreros de la época.

Si esa variedad de influencias e intereses es un factor enriquecedor de su obra, al mismo tiempo cabe señalar que una mirada de conjunto a sus trabajos deja una impresión de obra inacabada, en la cual se abren numerosas líneas de trabajo y aportes sugestivos pero que no fueron profundizados lo suficiente, ni coronados por un trabajo de envergadura, propia de su madurez. En cierto sentido da la impresión de ser una obra que alcanzó su punto más alto en un momento temprano, a mediados de los años 80, para luego ir opacándose lentamente. Muchos de sus aportes más originales no pueden desvincularse de su formación marxista y de su experiencia militante de más de una década: a partir de esa influencia y de su agudeza y talento como historiador Falcón pudo contribuir con una serie de hipótesis muy valiosas a la historia del movimiento obrero local.

Su producción escrita es relativamente escasa si tenemos en cuenta que su actividad como historiador profesional se extendió más de tres décadas. Muchas de sus hipótesis aparecen más esbozadas que desarrolladas, y es preciso realizar un rastreo minucioso de ideas y sugerencias dispersas en diferentes tramos de su obra, que como vimos está constituida principalmente por artículos en revistas nacionales y algunos libros de factura colectiva. Tal como coinciden en señalar la mayoría de sus discípulos, Falcón jugó un papel destacado en la formación de jóvenes investigadores, a quienes interesó en los temas vinculados a la historia de los trabajadores y estimuló a desenvolver muchas de las líneas de trabajo sugeridas en su obra. Valga entonces la recuperación de ese objetivo pedagógico siempre presente en su trabajo para las nuevas generaciones, que tenemos la tarea de hacer avanzar la historia de los trabajadores y la izquierda tomando lo mejor de lo realizado por quienes nos precedieron. 


\section{Referencias}

\section{a) Obras de Ricardo Falcón}

Falcón, Ricardo (1979), "Lucha de tendencias en los primeros congresos del Partido Socialista Obrero Argentino: 1896-1900", en Apuntes, N 1 , Amsterdam.

- (1981), Bibliografia para el estudio del movimiento obrero argentino en el siglo XIX, París: Centro de Estudios Histórico-Sociales de América Latina.

- (1982), "Conflicto social y régimen militar. La resistencia obrera en Argentina (marzo 1976-marzo 1981)", en Bernardo Gallitelli y Andrés A. Thompson (eds.), Sindicalismo y regimenes militares en Argentina $y$ Chile, Amsterdam: Centrum voor Studie en Documentatie van Latijns Amerika.

- (1984a), Los orígenes del movimiento obrero (1857-1899), Buenos Aires: Centro Editor de América Latina.

- (1984b), "Construir la historia de los trabajadores: de eso se trata", en Debates, año I, No 2, noviembre-diciembre.

- (1985a), L'immigration, les travailleurs et le mouvement ouvrier en Argentine: 1870-1912, tesis, Paris: EHESS.

- (1985b), "Los intelectuales y la política en la visión de José Ingenieros", en Anuario, $\mathrm{N}^{\circ} 11$, Rosario.

- (1986), El mundo del trabajo urbano, 1890-1914, Buenos Aires: Centro Editor de América Latina.

- (1987), "Izquierdas, régimen político, cuestión étnica y cuestión social (1890-1912)", en Anuario, No 12, Rosario.

- (1988), "Aspectos del proceso de formación de la clase obrera en Argentina (1870-1914)", en Revista de Historia, Centro de Investigaciones Históricas, Universidad de Costa Rica, $\mathrm{N}^{\mathrm{o}} 17$, enero-junio.

- (1989), "Problemas teóricos y metodológicos en la historia del movimiento obrero en Argentina", en Carlos Zubillaga (comp.), Trabajadores y sindicatos en América Latina, Montevideo: Consejo Latinoamericano de Ciencias Sociales.

- (1990), "Aspectos de la cultura del trabajo urbano, Buenos Aires y Rosario, 1860-1914", en Diego Armus (ed.), Mundo urbano y cultura popular: estudios de historia social argentina, Buenos Aires: Sudamericana.

- (1991), "El sindicalismo argentino en la encrucijada", Documentos de trabajo del CIESAL.

- (1992), "Inmigración, cuestión étnica y movimiento obrero (1870-1914)", en

Fernando Devoto y Eduardo Míguez, Asociacionismo, trabajo e identidad étnica, Buenos Aires: CEMLA-CSER-IEHS.

- (1992), "Elites urbanas, rol del Estado y cuestión obrera (Rosario, 1900-

1912)", en Estudios Sociales, N ${ }^{\circ} 3$, Santa Fe.

- (1992), "Cambios 'históricos' en la Argentina actual", La linea de sombra, $\mathrm{N}^{\mathrm{o}} 2$. 
- (1993), "Políticas neoliberales y respuestas sindicales (1989-1992)", en Oscar Moreno (comp.), Desafios para el sindicalismo en la Argentina, Buenos Aires: Fundación Friedrich Ebert-Legasa

- (1996), "La resistencia obrera a la dictadura militar", en Hugo Quiroga y

César Tcach (comps.), A veinte años del golpe. Con memoria democrática, Buenos Aires: Homo Sapiens.

- (1999), "Notas sobre la cuestión social en Argentina", en Cuadernos del CIESAL, $\mathrm{N}^{\circ}$ 6-7.

- (dir.) (2000a), Democracia, conflicto social y renovación de ideas (1916-1930).

Nueva historia Argentina, tomo 6, Buenos Aires: Sudamericana.

- (2000b), "Militantes, intelectuales e ideas políticas", en Ricardo Falcón

(dir.), Democracia, conflicto social... cit.

- (2001), La historia de Rosario, Rosario: Homo Sapiens Ediciones.

- (2005), La Barcelona argentina: migrantes, obreros y militantes en Rosario, 1870-1912, Buenos Aires: Laborde Editor.

- (2011a), "El renacimiento socialista", en Estudios Sociales, No 40, Santa Fe.

- (2011b), "Orígenes del movimiento socialista en Argentina. Prólogo. Capítulo I y II", Cuadernos del CIESAL, No 10, Rosario.

Falcón, Ricardo, Ronaldo Munck y Bernardo Gallitelli (1987), Argentina: From Anarchism to Peronism. Workers, unions and politics, 1855-1985, Londres y Nueva Jersey: Zed Press.

- y Hugo Quiroga (1987), Contribución al estudio de la evolución ideológica del Partido Comunista Argentino (1960-1984), Santiago de Chile: FLACSO.

-, Darío Macor y Alejandra Monserrat (1991), "Obreros, artesanos, intelectuales y actividad político-sindical. Aproximación biográfica a un perfil de los primeros militantes del movimiento obrero argentino", en Estudios Sociales, $\mathrm{N}^{\circ}$ 1, Santa Fe.

- y Alejandra Monserrat (1993), "Estado provincial, partidos políticos y sectores populares, el caso de Rosario: las elecciones de 1912 y los conflictos sociales", en Cuadernos del CIESAL, $\mathrm{N}^{\circ} 1$, Rosario.

- (1996), "Una vez más la Semana Trágica: estado de la cuestión y propuestas de discusión", en Cuadernos del CIESAL, $\mathrm{N}^{\circ}$ 4, Rosario.

- (2000), "Estado, empresas, trabajadores y sindicatos", en Ricardo Falcón (dir.), Democracia, conflicto social... cit.

- y Gabriela Benetti (1999), "Cuestión social, cuestión obrera, inclusión y exclusión en la argentina contemporánea”, en Anuario de la Escuela de Historia, $\mathrm{N}^{\circ} 19$, Rosario.

b) Otros trabajos citados

Armus, Diego (2011), "Historia laboral/historia local/historia nacional en Rosario al despuntar los años ochenta", en Estudios Sociales, $\mathrm{N}^{\circ} 40$, Santa Fe. 
Carozzi, Silvana (2011), "Una magdalena para Ricardo Falcón”, en Estudios Sociales, $N^{\circ} 40$, Santa Fe.

Devoto, Fernando (2011), "Ricardo Falcón, historiador del movimiento obrero", en Estudios Sociales, $N^{\circ} 40$, Santa Fe.

Franco, Marina (2008), El exilio: argentinos en Francia durante la dictadura, Buenos Aires: Siglo XXI.

Gotta, Claudia y María Luisa Mugica (2008), "Entrevista a Ricardo Miguel Falcón”, en Itinerarios. Anuario del CEEMI, año 2, $\mathrm{N}^{\circ} 2$, Universidad Nacional de Rosario.

Lobato, Mirta (2011), "Cuando un amigo se va", en Estudios Sociales, No 40, Santa Fe.

Mases, Enrique (2011), "Ricardo Falcón y el eclecticismo militante en la historia de los trabajadores en la Argentina", en Estudios Sociales, $N^{\circ}$ 40, Santa Fe.

Quiroga, Hugo (2011), "In vino veritas. Un viaje de exploración sobre una vida politica e intelectual", en Estudios Sociales, N 40, Santa Fe.

Prieto, Agustina (2011), "El gran pez", en Estudios Sociales, N ${ }^{\circ} 40$, Santa Fe.

Yannuzzi, María de los Ángeles (2011), "Ricardo Falcón: un último adiós", en Estudios Sociales, N 40, Santa Fe. 